\title{
Inter-Annual Changes in Vegetation Activities and Their Relationship to Temperature and Precipitation in Central Asia from 1982 to 2003
}

\author{
P. A. Propastin ${ }^{1,2,}$, M. Kappas ${ }^{1}$, and N. R. Muratova ${ }^{2}$ \\ ${ }^{1}$ Department of Geography, Georg-August University Göttingen, Goldschmidtstr, Göttingen 5, 37077, Germany \\ ${ }^{2}$ Laboratory of Remote Sensing and Image Analysis, Kazakh Academy of Science, Shevchenko Street, Almaty 15, 480040, Kazakhstan
}

Received 1 November 2006; revised 8 October 2007; accepted 3 January 2008; published online 1 December 2008

\begin{abstract}
We analyzed inter-annual trends in annual and seasonal vegetation activities in Central Asia from 1982 to 2003 and their correlation to climate variability using the NOAA/AVHRR Normalized Difference Vegetation Index (NDVI) dataset and a gridded climate dataset. The results indicate a significant increase in NDVI with a value of $11.35 \%$ over the growing season during the 22 -year period. Totalled over the entire vegetated area, about $35 \%$ of all pixels exhibited significant upward trend in growing season NDVI. We found that NDVI increase in spring was the main contributor to the general upward trend, the spring NDVI increased in more than $50 \%$ of all pixels and showed an average value of $13.58 \%$. Correlation analysis indicated a gradual rise in temperature as the only factor controlling trend in spring NDVI. Significant increase in vegetation activity was also identified for summer season, but its amplitude $(9.23 \%)$ and comprising area (25.13\% of all vegetated pixels) were less than for spring. Downward trends in growing season NDVI occurred in $2.17 \%$ of the total vegetated area. The greening trends of spring, growing season and summer NDVI strongly related with the climatic parameters: for each land cover type, we found significant correlation with spring temperature and total precipitation; $75 \%$ of all upward trends in growing season NDVI were explained by the combination of these both variables. We found that the NDVI trends and their climatic correlates demonstrate great spatial variability at the scale of individual land cover types and at per-pixel scale and proofed that the land use change caused by the constitutional change in the 1991 has substantial control on the vegetation trends. Increased vegetation growth indicated through the analysis of NOAA AVHRR NDVI time-series suggests an increasing carbon stock in biomass of ecosystems in Central Asia.
\end{abstract}

Keywords: central Asia, NDVI time-series, climate change, vegetation response, correlation analysis

\section{Introduction}

From recent published studies it is clear that the vegetation on the surface of the Earth is rapidly changing. Change is occurring to the phenology, to distribution of vegetation on the Earth surface and to the annual dynamics of photosynthetic activity by vegetation. For example, recent studies have demonstrated linear increase in plant growth over the last two decades especially in the northern high latitudes of Eurasia and North America between $40^{\circ} \mathrm{N}$ and $70^{\circ} \mathrm{N}$ (Muneni et al., 1997, 1998; Tucker et al., 2001). This inter-annual increase in photosynthetic activity has been associated with a lengthened plant growing season due to an earlier green-up of vegetation (Potter and Broocks, 1998; Tucker et al., 2001; Tateishi and Ebata, 2004). Further, inter-annual trends in vegetation activeties have been also analysed at global scale (Kowabata et al., 2001; Yang et al., 2005; McCloy et al., 2005), and at regional

* Corresponding author. Tel.: + 49(0)55139 7979; fax: + 49(0)55139 8020. E-mail address: ppropas@ uni-goettingen.de (P. A. Propastin).

ISSN: 1726-2135 print/1684-8799 online

(C) 2008 ISEIS All rights reserved. doi:10.3808/jei.200800126 scale for China (Xiao and Moody, 2004) and in the Sahel (Anyamba and Tucker, 2005).

Climate is the most important factor affecting vegetation condition and its development over the time. Much of the changes in photosynthetic activity by vegetation is being driven by climate change, especially global warming. According to the Intergovernmental Panel on Climate Change (IPCC, 2001), the Earth's climate has warmed by $0.6^{\circ} \mathrm{C}$ over the past 100 years. Certainly, global warming controls vegetation dynamic and its inter-annual change (Chen et al., 2004). Thus, increases in spring temperatures following by an earlier start of vegetation growing season are reported to be the main driving force for increase in vegetation growth in the northern high latitudes of Eurasia and North America (Tucker et al., 2001). For China, temperature also plays a major role in explaining the greening pattern (Xiao and Moody, 2004). In other cases, increase in vegetation growth over the last two decades is controlled by rainfall increase (Tucker and Nicholson, 1999). But changes in vegetation activity can also result from a variety of other environmental factors, such as El Nino-Southern Oscillation (ENSO) events (Anyamba et al., 2001; Gutmann et al., 2000) or human activities (e. g. landuse). 
The most recent studies of changes in vegetation activity at global or regional scales have been based on the using of data time-series from Advanced Very High Resolution Radiometer (AVHRR) launched by the National Oceanic and Atmospheric Administration (NOAA) in 1981. The AVHRR product commonly used for these investigations is the Normalized Difference Vegetation Index (NDVI). The vegetation absorbs a great part of incoming radiation in the visible portion of the spectrum (VIS $=380$ to $730 \mathrm{~nm}$ ) and reaches maximum reflectance in the near-infrared channel (NIR $=730-1100$ $\mathrm{nm})$. The NDVI, defined as ratio (NIR - VIS) / (NIR + VIS), represents the absorption of photosynthetic active radiation and hence is a measurement of the photosynthetic capacity of the canopy. Negative NDVI values indicate non-vegetated areas such as snow, ice, and water. Positive NDVI values indicate green, vegetated surfaces, and higher values indicate increase in green vegetation. The NDVI is established to be highly correlated to green-leaf density, absorbed fraction of photosynthetically active radiation and above-ground biomass and can be viewed as a surrogate for photosynthetic capacity (Justice et al., 1985; Tucker and Sellers, 1986).

In this study, we examine changes in vegetation activity seasonally and annually at a regional scale for Central Asia using the NDVI dataset derived from Pathfinder AVHRR Land from 1982 to 2003. The inter-annual changes were mapped and measured for all vegetation pixels, and for each vegetation type. In addition, climate effects on NDVI trends over the period 1982-1998 were examined using air temperature and precipitation gridded dataset (New et al., 2000).

\section{Background}

\subsection{Study Region}

Kazakhstan and the other republics of the former Soviet Union in the region of Central Asia (Uzbekistan, Turkmenistan, Kirgizstan and Tajikistan) comprise more than 5.5 million $\mathrm{km}^{2}$ of territory. In spite of climate aridity, the ecosystems of the Central Asia represent a gigantic reservoir of carbon, and, on the one hand, they play a very significant role in the global change, on the other hand, they are very sensitive to the contemporary climate change (Lubimtseva et al., 2005). Both the climatic conditions and physio-geographic patterns vary significantly within this region. Climatic type, soil properties, vegetation type, and landforms show a high variance within the region's eco-geographic zones.

Most of the Central Asia's territory is occupied by dry lands. The deserts, semi-deserts and steppes of Central Asia and Kazakhstan have a strongly continental climate. The region is usually divided into two sub-regions: northern (mainly Kazakhstan) and southern or Iran-Turanian (Petrov, 1976). The boundary between these sub-regions is rather poorly defined but it lies at approximately 45 to $46^{\circ} \mathrm{N}$. Summers in the southern sub-region are hot and substantially dry, winters are moist and relatively warm. The northern sub-region is characterized by hot and moist summers and very cold winters. The temperature amplitude in this sub-region is relative high: average January temperature is below $-20^{\circ} \mathrm{C}$ and average
July temperature is about 26 to $28^{\circ} \mathrm{C}$. The annual amount of precipitation ranges here from about $200 \mathrm{~mm}$ to more than $450 \mathrm{~mm}$. The most part of precipitation falls during warm period from March to October. In the southern sub-region winters are milder with the minimum winter temperature between -10 and $0^{\circ} \mathrm{C}$. The average July temperature is about 30 to $32^{\circ} \mathrm{C}$. Precipitation in this sub-region has an annual amount of 80 to $200 \mathrm{~mm}$ and a spring maximum.
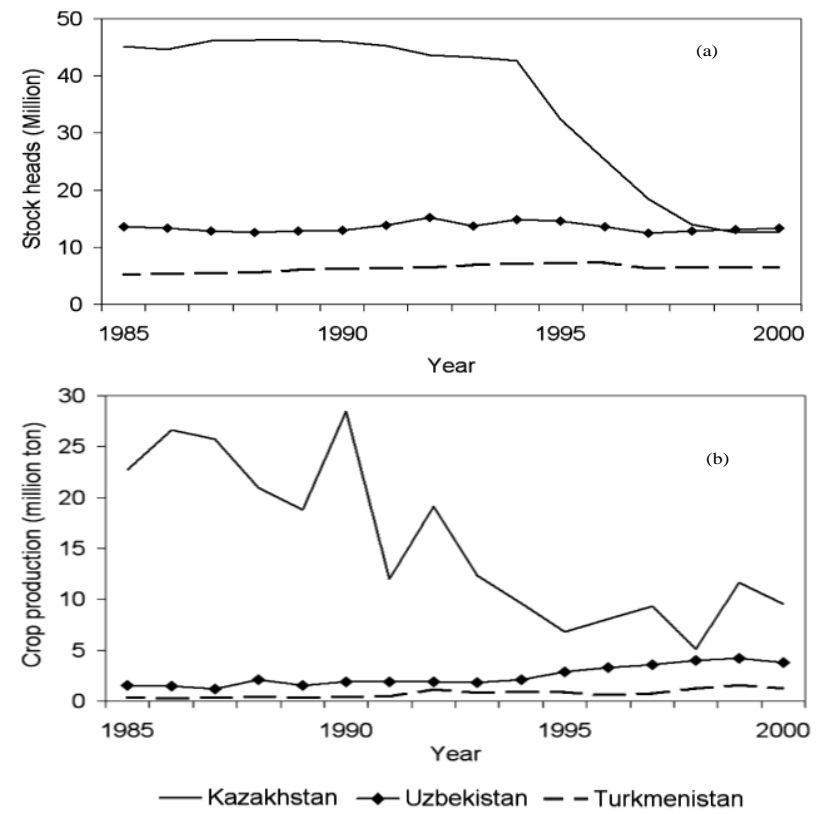

Figure 1. Dynamics of the major types of agricultural production in the three largest central Asian countries: (a) the total animal production; (b) the crop production.

\subsection{Brief Overview of the Recent Environmental Change in Central Asia}

In the beginning of the 1990s, a rapid environmental change was caused by the collapse of the Soviet Union and the collapse of the planed economic system. Following these political events, a massive land-use changes expressing in a decrease of human pressure on the ecosystems occurred over the whole region. The most significant changes are associated with Kazakhstan, the area largest country in the region. Kazakhstan has been also characterized by the largest domestic and agricultural production among the Central Asian countries. For example, wheat area and production in Kazakhstan dropped dramatically from about 15 Mha and $18 \mathrm{MMt}$ to less than $8 \mathrm{Mha}$ and $5 \mathrm{MMt}$, correspondingly (Figure 1). The number of cattle and sheep is declined by about $60 \%$. Uzbekistan and Turkmenistan have not experienced any significant change of the stock number during the 1990s, and even increased their production of crops. Cotton production in the region dropped drastically from about 6.2 to 3.0 MMt in Uzbekistan and from 3.35 to about 1.60 MMt in Kazakhstan. Turkmenistan remained their production value of cotton on the level of 1.20-1.30 MMt. The environmental change in Tadjikistan and Kyrgizstan, two area smallest countries, did 
not experience any notable changes in land use. Most of their territory is mountainous and has been only poorly used for agricultural extensive production.

All environmental changes should be reflected in the vegetation conditions and their time-trends. De Beurs and Henebry (2004) reported that the institutional and land use changes in Kazakhstan affected land surface phenology at spatial resolution and extend relevant to meso-scale meteorological models. Robinson et al. (2002) investigated land degradation and desertification in pasture lands of desert and semi-desert zone of the central Kazakhstan and found very good conditions of the pastures: "the pastures are now either ungrazed, or grazed by a tiny fraction of the animals which would previously have used them, than overgrazed".

The region of Central Asia has experienced a warming trend in order of $1-2^{\circ} \mathrm{C}$ since the beginning of the $20^{\text {th }}$ century. This might have a strong impact on the regional temperature and precipitation regimes and also on vegetation cover. Great spatial variability in temperature and precipitation trends can be observed at the landscape scale and seems to be controlled by land use change and land cover characteristics (Lubimtseva et al., 2005). A better understanding of the interrelationships between climate, vegetation cover and land-use changes will help improve our understanding of the role of Central Asia's ecosystems in the global carbon cycle and global climate change.

\section{Data and Methods}

\subsection{NOAA AVHRR NDVI}

To monitor temporal variations and trends of vegetation activities we used the Global Inventory Monitoring and Modelling System (GIMMS) NDVI dataset compiled at $8 \mathrm{~km}$ spatial resolution from the NOAA AVHRR satellite data by the Global Inventory Monitoring and Modelling Studies (GIMMS) research group. The data are originally processed as 15-day composites using the maximum value procedure to minimize effects of cloud contamination (Holben, 1986). For this research, we created monthly composites from the 15-day composites. These monthly NDVI data for consecutive three and noun months were averaged to generate seasonal and growing season NDVI for each year. The data cover the period from 1982 to 2003 .

Unfortunately, the long-time series of satellite data always remain noises associated with residual atmospheric effects, orbital drift effects, inter-sensor variations, and stratospheric aerosol effects (Myneni et al., 1998; Tucker et al., 2001) that can produce significant errors by applications. These noises have been already significantly reduced in the GIMMS dataset by a series of corrections, including temporal compositing, spatial compositing, orbital correction, calibration for sensor differences, and atmospheric correction (Pinzon et al., 2004). In order to improve the dataset further, we have made additional calibration of the GIMMS NDVI data using a method described by Los (1993): the NDVI timeseries were calibrated against three time invariant desert tar- gets located in the Big Arabian Desert, Nubian Desert and Taklimakan Desert. The vegetation-free surface of these desert targets considered to be stable throughout the analyzed time-period and should exhibit NDVI with value of near zero. Any temporal deviations of the NDVI value from zero have to be attributed to a non-vegetation noise and are to be corrected. This method removes effects of sensor degradation remaining in the original GIMMS data and corrects drift between different sensor systems. In addition to that, we removed noisy pixel areas characterized by exceptionally low NDVI values relatively to their pixel neighbourhood. These pixels were replaced by a mean value calculated from their spatial neighbourhoods.

\subsection{Climate Data}

Global data set of air temperature and precipitation were used (New et al., 2000). This grid raster data are interpolated from climate station records and has a spatial resolution of $0.5^{\circ}$. These data are available from the Climatic Research Unit (CRU), School of Environmental Sciences, University of East Anglia (http://www.cru.uea.ac.uk/). For this work, the monthly precipitation data were resized to $8-\mathrm{km}$ resolution to get a regional vision and to match the $8-\mathrm{km}$ NDVI dataset. In order to minimize information distortion and loss during the conversion process, we used an interpolation method known as kriging with external drift (KED). A tile plot for the study area of the GTOPO30 digital terrain model was used in the KED process as the second variable representing the elevation (http://edcwww.cr.usgs.gov/landdaac/gtopo30/gtopo30.html). The original GTOPO30 tile plot was resampled to $8-\mathrm{km}$ resolution. The use of an additional variable, altitude significantly decreased all negative consequences on the resizing of the source $0.5^{\circ}$ dataset. To assess the accuracy of this data preparation, we randomly reserved 10 weather stations from the interpolation for one of the monthly records and compared interpolated and recorded values. Average error was less than $6 \%$. It means that the interpolation approach worked effectively.

\subsection{Land-cover Data and Approach to Treat Them}

The land cover data in the study area were taken from the digital land-cover map derived from Moderate Resolution Imaging Spectroradiometer (MODIS) by Friedl et al. (2002) that have been accessible in the United States Geological Survey (USGS) archive centre. Originally, this map has $1 \mathrm{~km}$ spatial resolution and was resampled to $8 \mathrm{~km}$ resolution. There are 10 mean land cover types in the study area (Figure 2, Table 1).

We were aware of the problem that the map represents a distribution of the land covers and their areas corresponding to the baseline year 2001. Certainly, land cover parameters were not constant during the whole study period and may exhibit significant alterations from year to year. As the study period spanned over twenty years, there could be significant land cover changes due to both human activities and natural 
factors. A classic example of land cover's area oscillations controlled by climate has been shown for Sahara's boundaries by Tucker and Nicholson (1999). However, in this work and in other related studies on vegetation trends it has been not possible to obtain individual maps for every year from the time-period to be studied. Thus, the studies by Yang et al. (2005) and Xiao and Moody (2004) have performed their research both at the global and regional scale also using only one map of land covers associated with a baseline year and have traced vegetation trends of individual land cover types operating with their areas computed for the baseline year. In these on other related studies any change in land cover has been assumed to represent vegetation change associated with increasing or decreasing photosynthetic activity and considered to represent vegetation dynamics within a certain land cover type. For example, if any area of cropland has been abandoned and is undergoing a restoration process, this area belongs further to cropland even though its vegetation trends may distinguish from the surrounding cropland areas. However, the vegetation trends observed in this area and in other similar abandoned areas influence significantly the magnitude of the general trend associated with this land cover type and influence our interpretation of that. In order to detect variability of vegetation trends within each land cover type, we carried out corresponding analysis also at the per-pixel scale.

Table 1. The Total Number of Pixels within Each Land-Cover Type, Its Area, and Percentage in Central Asia Based on the 2001 MODIS Land-cover Map (Friedl et al., 2002)

\begin{tabular}{llll}
\hline Land-cover type & $\begin{array}{l}\text { Number } \\
\text { of Pixels }\end{array}$ & $\begin{array}{l}\text { Area, million } \\
\mathrm{km}^{2}\end{array}$ & Percentage, \% \\
\hline Cropland & 9008 & 0.609 & 10.92 \\
Irrigated cropland & 4163 & 0.266 & 4.79 \\
Cropland mosaic & 18535 & 1.186 & 21.67 \\
Grassland & 26951 & 1.725 & 31.32 \\
Shrubland & 13186 & 0.844 & 15.20 \\
Savanna & 2077 & 0.133 & 2.30 \\
Wetland & 3135 & 0.201 & 3.61 \\
Forest & 6616 & 0.423 & 7.59 \\
Tundra & 332 & 0.021 & 0.38 \\
BSV & 2771 & 0.177 & 3.13 \\
Total & 86774 & 5.578 & 100 \\
\hline
\end{tabular}

* BSV = Barren or sparsely vegetated.

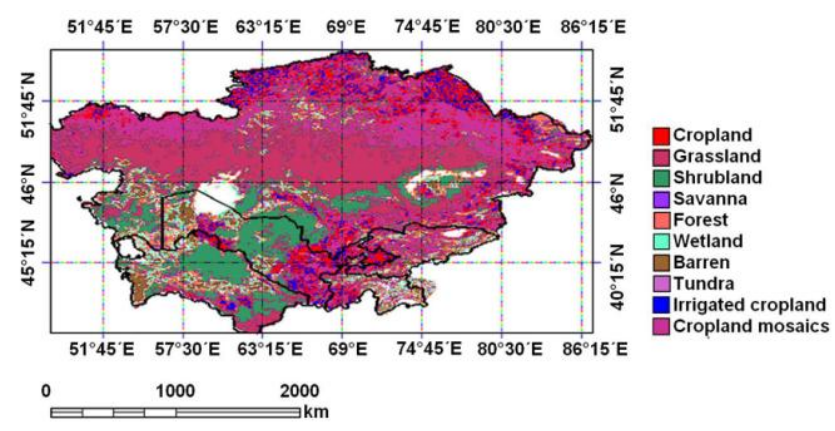

Figure 2. Land-cover distribution in Kazakhstan and the middle Asia based on the MODIS land-cover map.

\subsection{Methods}

This study objected to analyse inter-annual vegetation change and its relationship to climatic factors. Any change may be detected with sufficient statistical significance only than when the time-period of observation is enough long. High oscillations of a variable to be analysed show a strong negative influence on the results of the inter-annual analysis. Great amplitude of the variable variance reduces the probability of trend determination. The higher is the amplitude of the oscillations of the variable around the mean value the lower is the statistical significance by trends with a similar amplitude but a different variability of the variable to be analysed. It means that for a certain determination of trends by variables with high amplitude of oscillations one needs to analyse a longer time-period than by low-oscillating variables. Unfortunately for trends detection, the vegetation cover in drylands'ecosystem is characterized by high inter-annual variability which is caused by high variance of climatic factors, particularly precipitation (Mainquet, 1999; Herrman and Huttchinson, 2005). However, the length of the time-period analysed in this study (1982 to 2003) was limited through the length of the USGS data archive. We used the whole period of the existing time-series of the NOAA AVHRR data available at the time of work. An extension to recent years could be possible by using data from other satellites such as SPOTVegetation or MODIS. These data with the original spatial resolution of 1-km might be combined with the 8-km AVHRR dataset only after a very serious analysis and modelling their compliance to the last (Tucker et al., 2005). Our work did not object any extensions of the available AVHRR dataset, therefore, we focused the trend analysis to the period 1982-2003. While interpreting the results of the trend analysis we took into account high variability of spring season NDVI which was reflected in relatively low values of trend's $\mathrm{R}^{2}$ and low values of statistical significance but a high change magnitude (see Part 5.1.2, Table 3).

We generated spatially averaged time series of mean NDVI, mean temperature, and total precipitation for all vegetated pixels, and for each individual land-cover type presented on the map in Figure 2. Each time-series was standardized by subtracting the mean of the series from the original data and then dividing by the standard deviation of the series in order to constrain the variance of these time series to the same range and make their inter-comparison. The linear trends of spatially averaged NDVI were determined by linearly regressing these variables as a function of time over the period from 1982 to 2003 for each category of spatial aggregation. We than analysed the correlations between NDVI and climate data to assess the associations between vegetation changes and climate changes on a land cover type basis. These analyses were repeated for spring (March to May), summer (June to August), autumn (September to November) and for the whole growing season (March to November) using seasonal mean NDVI, seasonal mean temperature, and seasonal totals of precipitation. A $p$-value of 0.05 was used as the test criteria for significance of all correlation statistics. The results of these analyses for each land cover type (trend slope, total increase/decrease from 
the beginning of the study period, the determination coefficient $\mathrm{R}^{2}$ for the trend, correlation coefficient between NDVI and climatic parameters) were presented in tables.

However, the trends of spatially aggregated NDVI may hide the geographical variability of NDVI trends over space. The computation of a spatial average over certain geographical regions is a very convenient tool for the analysis of time series of remotely sensed data which has been often used in related studies (Wang et al., 2003; Xiao and Moody, 2004). It eliminates almost all noise contained in a dataset and allows an easy visualisation of time series and its interpretation together with other datasets. A disadvantage of a regional averaging is that it also excludes from analysis possible local variations of the relationship to be analysed and is appropriative only to describe a general character of relation between defined variables (Foody, 2003; Propastin and Kappas, 2008). We thus analysed the spatial patterns of the NDVI trends from 1982 to 2003 . We identified the vegetated pixels with linear trends in NDVI that are statistically significant $(p<0.05)$ over the study period. For these pixels, we further analysed the correlations between NDVI and the climate variables. These analyses were repeated for each season and for the entire growing season. The local variances in the linear NDVI trends as well as the relative strength of associations between NDVI and the climate variables were highlighted and mapped. For each land cover type we also evaluated areas (in $\%$ and in $\mathrm{km}^{2}$ ) that exhibited significant linear NDVI trends and areas where these trends were supported by climate change. The spatial resolution of the NDVI and climate data $(8 \mathrm{~km})$ enabled us to look into local circumstances of the relationships between vegetation and climate dynamics. Hence, in the terms of the analysis scale we obtained results at three different spatial scales: at the regional scale - averaged over the entire region, at the scale of individual land cover types, and for each pixel (the per-pixel scale).

In order to find out to what degree observed general trends of NDVI were driven by the compound effect of rainfall and temperature, we computed multiple correlation coefficient with growing season NDVI as a dependent variable and spring temperature, summer temperature, and precipitation as independent variables. We repeated this correlation analysis for every pixel with significant trend in NDVI and measured areas occupied by pixels with significant trend and significant multiple correlation coefficient. After that a percentage of pixels whose NDVI trends had been driven by the combine climate effect were calculated in each land cover type.

Certainly, the trends of vegetation were not monotonic increasing or decreasing over the period of 1982-2003, particularly in those areas where substantive changes of human activity occurred. Considerable local fluctuations (e.g. within just a several years, particularly associated with the years immediately after the collapse of the socialistic economic system) could be expected in these areas. In order to demonstrate such fluctuations we analysed and discussed local NDVI profiles at a number of key sites whose evolution of vegetation cover is characteristically for this transition period.

\section{Results}

\subsection{Trends in Spatially Integrated NDVIs}

\subsubsection{Trends in Growing Season NDVI}

The spatially averaged time-series of growing season NDVI exhibited a significant upward trend with a slope of 0.0019 and an increase of $11.35 \%$ for all vegetated pixels over the period 1982-2003 (Table 2, Figure 3a). The determination coefficient of the trend is very high, $\mathrm{R}^{2}=0.70$. NDVIs also exhibited significant upward trends for every land-cover type. The magnitudes of NDVIs trends varied by land-cover type, with the highest total increase value of $16.92 \%$ for wetland, and the lowest value of $7.92 \%$ for forest. For cropland mosaics, grassland, the total increase of NDVI during 22 years was a little below $10 \%$, while for cropland, savanna and $\mathrm{BSV}$, that was a little over $10 \%$. For irrigated cropland, the growing season NDVI increased by $14.42 \%$, for shrubland, it increased by $11.10 \%$, and for tundra vegetation by $13.46 \%$. The determination coefficient of the trend regressions, $\mathrm{R}^{2}$, ranged from 0.47 (barren or sparsely vegetated areas) to 0.76 (tundra).
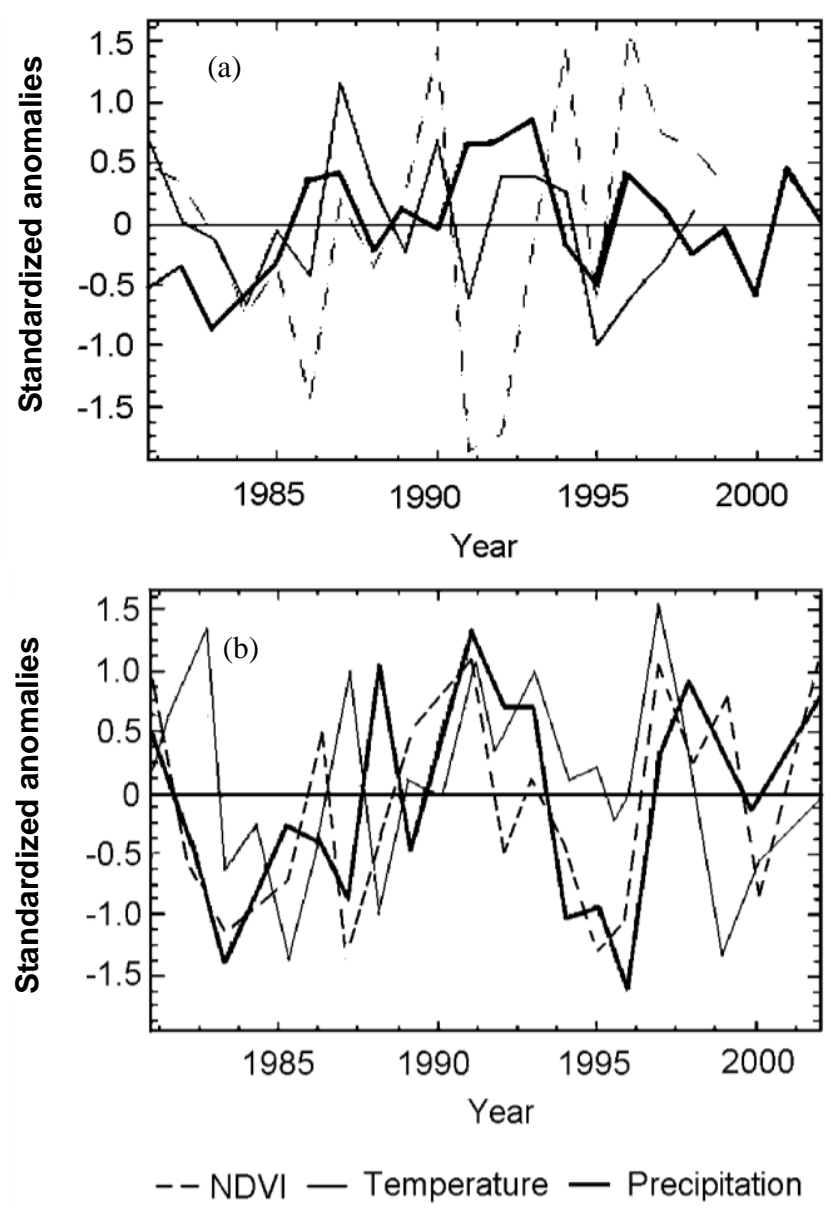

Figure 3. Spatially averaged time series of growing season NDVI, mean temperature, and total precipitation: (a) all vegetated pixels; (b) grassland. 


\subsubsection{Trends in Seasonal NDVI}

The spatially averaged time-series of seasonal NDVIs showed upward trends in spring and summer in the most landcover types (Tables 3 and 4). The total increase averaged for all vegetated pixels was $13.58 \%$ for spring (Figure $4 \mathrm{a}$ ), and $9.23 \%$ for summer, with $\mathrm{R}^{2}=0.17$ and 0.57 , respectively. The significance of the spring NDVI trends was substantially lower than that of the summer trends, $p$-value of the spring trends in different land cover types ranged between 0.03-0.08. However, the trends of spring NDVI were generally characterized by a relatively high magnitude. The trend magnitude of spring NDVI ranged from $11.91 \%$ to $16.70 \%$; that of summer NDVI ranged from $7.83 \%$ to $16.92 \%$, for BSV and tundra. The reason for the relatively low significance of the spring NDVI trends may be a high inter-annual variability of the spring NDVI. We computed coefficient of variation (CV) for inter-annual and inter-seasonal NDVI time series in each of the land cover type and found that the CV computed with the spring NDVI showed values which were higher than the CV for other seasons. An example is presented in Figure $4 \mathrm{~b}$.
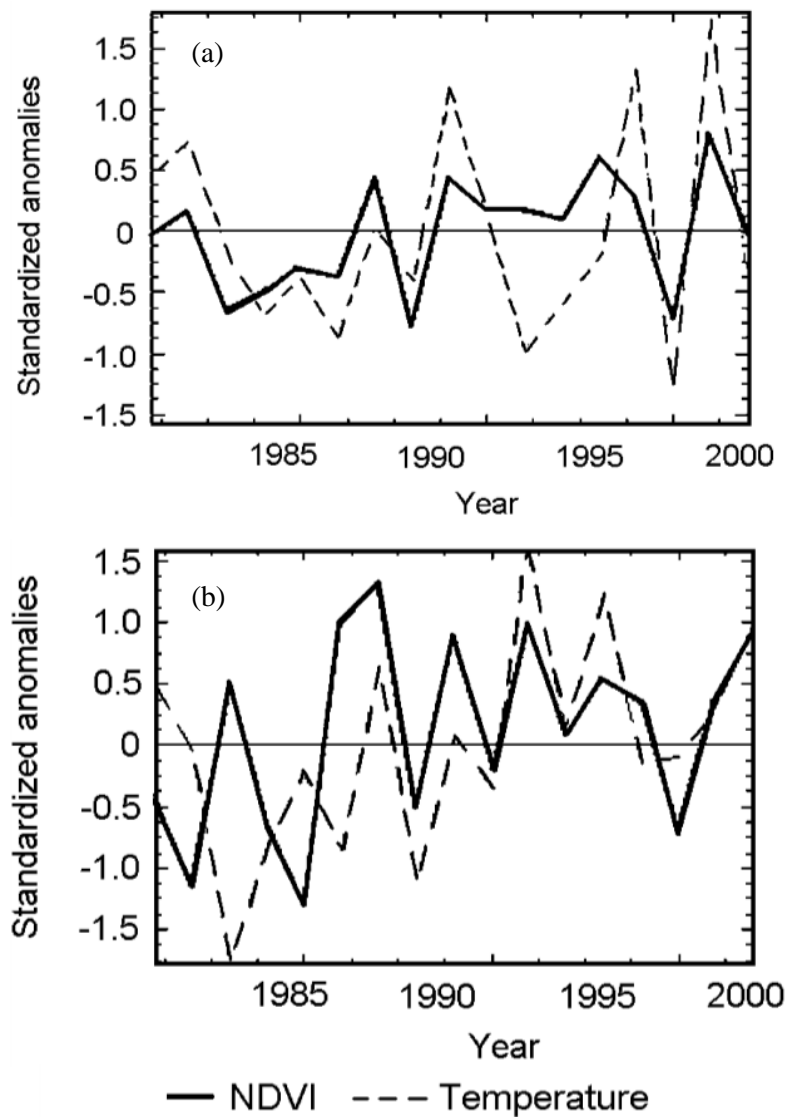

Figure 4. Spatially averaged time series of spring NDVI and mean temperature: (a) all vegetated pixels; (b) cropland.

Forest showed the highest increase in spring NDVI, suggesting its trend in vegetation activity is primary attributed to spring rather than the whole growing season, summer or autumn season. This is consistent with results from previous studies undertaken in similar latitudes at global and regional scales. The reason for the higher change rates of forest vegetation activity in spring corresponds to general upward trends in winter and spring temperatures (Kawabata et al., 2001; Tucker et al., 2001; Xiao and Moody, 2004). Cropland, cropland mosaic, irrigated cropland, savanna and wetland, also showed high values of the trend in spring NDVI over 1982 to 2003 , with a total increase of 14.91, 16.62, 15.57, 14.75 and $12.09 \%$, respectively. The most land-cover types, except irrigated cropland, wetland and tundra, exhibited trends in summer NDVI with a total increase over the study period $<10 \%$. Autumn NDVI exhibited an upward trend only in wetland and tundra with a magnitude value of $8.96 \%$ and $12.40 \%$ respectively. Other land-cover types demonstrated no significant trend in NDVI for autumn (data not shown).

Table 2. Trends of Spatially Averaged Time-Series of Growing Season NDVI over 1982-2003

\begin{tabular}{llll}
\hline Land-cover type & Trend slope & Total increase, \% & $\mathrm{R}^{2}$ \\
\hline Cropland & 0.0023 & 10.61 & 0.57 \\
Irrigated cropland & 0.0026 & 14.42 & 0.68 \\
Cropland mosaic & 0.0019 & 9.65 & 0.51 \\
Grassland & 0.0013 & 9.07 & 0.52 \\
Shrubland & 0.0012 & 11.10 & 0.62 \\
Savanna & 0.0015 & 10.54 & 0.61 \\
Wetland & 0.0042 & 16.92 & 0.71 \\
Forest & 0.0022 & 7.92 & 0.57 \\
Tundra & 0.0011 & 13.46 & 0.76 \\
BSV & 0.0009 & 10.01 & 0.47 \\
Total & 0.0019 & 11.35 & 0.70 \\
\hline
\end{tabular}

$* \mathrm{BSV}=$ Barren or sparsely vegetated.

Table 3. Trends of Spatially Averaged Time-Series of Spring NDVI over 1982-2003

\begin{tabular}{llll}
\hline Land-cover type & Trend slope & Total increase, \% & $\mathrm{R}^{2}$ \\
\hline Cropland & 0.0028 & 14.91 & 0.18 \\
Irrigated cropland & 0.0019 & 16.62 & 0.21 \\
Cropland mosaic & 0.0022 & 12.09 & 0.13 \\
Grassland & \multicolumn{2}{l}{ No significant trend } & \\
Shrubland & 0.0012 & 11.91 & 0.15 \\
Savanna & 0.0018 & 14.75 & 0.18 \\
Wetland & 0.0022 & 15.57 & 0.18 \\
Forest & 0.0037 & 16.70 & 0.15 \\
Tundra & No significant trend & \\
BSV & 0.0012 & 11.91 & 0.17 \\
Total & 0.0019 & 13.58 & 0.18 \\
\hline
\end{tabular}

* BSV = Barren or sparsely vegetated.

\subsection{Spatial Patterns of NDVI Trends}

Since spatial averaging hides the geographical variability of NDVI, it is to expect that the NDVI trends will exhibit some spatial patterns within every land-cover type. These spatial patterns may be highlighted through calculation of trends on a pixel-by-pixel basis. We identified all vegetated pixels with linear trends in NDVI that were statistically significant. 
This analysis was repeated for each season. It was also to expect that not all pixels should show upward trends in NDVI, some pixels may exhibit downward trends. That was supported by the statistical analysis. Over the entire study region, the results of our calculations show that $34.47 \%$ of all vegetated pixels for the growing season exhibited significant upward trend over the study period, and only $2.17 \%$ of all pixels exhibited significant downward trend (Table 5). Greening patterns are mostly observed in the northern and southern portions of the region (Figure 2). Downward trends in growing season NDVI were mainly concentrated in the middle part, around the Aral See and in the space between the Aral Sea and the Caspian Sea.

Table 4. Trends of Spatially Averaged Time-Series of Summer NDVI over 1982-2003

\begin{tabular}{llll}
\hline Land-cover type & Trend slope & Total increase, $\%$ & $\mathrm{R}^{2}$ \\
\hline Cropland & 0.0021 & 7.97 & 0.39 \\
Irrigated cropland & 0.0027 & 11.99 & 0.58 \\
Cropland mosaic & 0.0020 & 8.41 & 0.36 \\
Grassland & 0.0014 & 9.11 & 0.37 \\
Shrubland & 0.0008 & 7.91 & 0.36 \\
Savanna & 0.0013 & 7.89 & 0.44 \\
Wetland & 0.0055 & 16.43 & 0.67 \\
Forest & No significant trend & \\
Tundra & 0.0017 & 16.95 & 0.77 \\
BSV* & 0.0008 & 7.83 & 0.36 \\
Total & 0.0017 & 9.23 & 0.57 \\
\hline
\end{tabular}

* BSV = Barren or sparsely vegetated.

The percentage of pixels with upward NDVI trends varied substantially by land-cover type. Most of the pixels with positive trends have been found within the following land covers: cropland $(49.52 \%)$, irrigated cropland $(55.65 \%)$ and cropland mosaics $(42.68 \%)$. These land cover types were the major contributors to the general greening trend in Central Asia. For grassland, the area largest land cover type, $20.61 \%$ of all pixels had positive trend. Essential area of positive NDVI trend was also observed in shrubland (1907 pixels or $14.5 \%$ from the entire shrubland's area) and forest (1985 pixels or $30.03 \%$ from the forest area).

In the most land cover types percentages of pixels with downward trends are very small: $1.68 \%$ in cropland and irrigated cropland, $1.53 \%$ in cropland mosaics, $1.41 \%$ in grassland, and $1.50 \%$ in tundra. The other land cover classes exhibit some higher percentage, between 2.26 and 5.42\%. In spite of the little individual percentage, cropland, grassland and shrubland were the major contributors to the entire area taken by the negative NDVI trends.

The percentage of pixels with upward or downward trends also varied from season to season (Table 5). The highest percentage of pixels with upward trend is observed for spring NDVI, $50.31 \%$. The greening pattern in spring is more immense than in any other season (Figure 5b). Particularly high percentage showed cropland, irrigated cropland and cropland mosaic with a value of $70.45,73.50$ and $55.58 \%$, respectively. Pixels with positive trends in spring NDVI are densely distributed across the whole study region, except its middle part. There, over the swath between the Caspian Sea and the Balkhash Lake, pixels with negative trend are located. Altogether, $4.70 \%$ of all vegetated pixels had the negative trend in spring.

In summer, $25.13 \%$ of all vegetated pixels showed positive trends in NDVI over 1982 to 2003 . These areas are mainly distributed in the northern part of the study region, and sparsely in the southern and eastern parts (Figure 5c). Even though the highest magnitude of the summer NDVI increase was associated with tundra (about $60 \%$ from the beginning of the period), but cropland, irrigated cropland, cropland mosaics, and grassland were the major contributors to the area characterized by the increasing photosynthetic activity of vegetation. The summer season revealed the highest percentage of pixels with downward trend, $10.12 \%$ of total pixel amount. These pixels occupied large areas in central swath of the region. The most part of them is located in the space between the Aral Sea and the Balkhash Lake. Speaking about the individual contribution of the seasons to the general growing season vegetation trend, summer season was the major contributor to the negative trends in growing season NDVI, whereas grassland, shrubland, savanna and barren were the major contributors in terms of the area occupied by the downward trends.

In autumn, positive NDVI trends were observed only for a small part of the total pixel number, $16.11 \%$. Relatively high increases in NDVI accounted for 20.34, 24.05, 21.67 and $39.53 \%$ of the total area of savanna, forest, wetland and tundra. For other land-cover types, percentage of pixels with positive trend is low. NDVI increasing trends were mostly found in the southern stripe of the region, and only densely in the north (Figure $5 \mathrm{~d}$ ). On the whole, $4.96 \%$ of all vegetated pixels had negative trend in autumn NDVI. Vegetation activity decreased in some parts of the central area, even though the majority of pixels with downward trends are concentrated in the westernmost part.

\subsection{Effects of Precipitation and Temperature on NDVI Trends}

4.3.1. Relationship between Spatially Averaged NDVI Timeseries and Precipitation

According to recent studies, precipitation has a strong effect on inter-annual variability of vegetation activity especially in dry regions (Yang et al., 1997; Richard and Poccard, 1998; Wang et al., 2003). It is likely that any trend in NDVI may reflect trend in precipitation amount over the time. For example, the contemporary greening patterns in the Sahel are supported to be driving by an increasing trend in rainfall (Anyamba and Tucker, 2005). Existence of high correlation between inter-annual vegetation activity and precipitation has been used to detect areas of land degradation and desertification in the Near East and in Senegal (Evans and Geerken, 2004; Li et al., 2004). The degree of the control on NDVI through precipitation, however, depends on vegetation type, soils, and management practices (Nicholson and Farrar, 1994; 
Table 5. Percentage (\%) of Pixels with Significant upward or downward Trends in NDVI within Each Land-cover Type

\begin{tabular}{lllllllll}
\hline \multirow{2}{*}{ Land cover } & \multicolumn{2}{c}{ Growing season } & \multicolumn{2}{c}{ Spring } & \multicolumn{2}{c}{ Summer } & \multicolumn{2}{c}{ Autumn } \\
\cline { 2 - 8 } & upward & downward & upward & downward & upward & downward & upward & downward \\
\hline Cropland & 49.52 & 1.68 & 70.45 & 1.57 & 27.15 & 7.08 & 17.65 & 4.54 \\
Irr. cropland & 55.65 & 1.53 & 73.50 & 1.39 & 27.47 & 7.05 & 20.17 & 4.62 \\
Crop. mosaic & 42.68 & 1.43 & 55.58 & 1.71 & 31.56 & 6.52 & 14.56 & 3.59 \\
Grassland & 20.61 & 1.41 & 38.89 & 5.74 & 21.75 & 14.47 & 12.42 & 5.19 \\
Shrubland & 14.63 & 3.48 & 44.22 & 7.05 & 15.94 & 14.60 & 16.14 & 4.81 \\
Savanna & 33.41 & 4.35 & 54.70 & 6.56 & 26.90 & 13.18 & 20.34 & 5.61 \\
Wetland & 21.43 & 4.88 & 46.52 & 10.25 & 29.56 & 14.95 & 21.67 & 7.95 \\
Forest & 30.03 & 2.26 & 50.91 & 8.82 & 27.63 & 12.10 & 24.04 & 5.78 \\
Tundra & 22.28 & 1.51 & 26.74 & 21.39 & 60.85 & 1.93 & 39.53 & 3.10 \\
BSV & 21.17 & 5.42 & 43.27 & 13.03 & 27.15 & 18.59 & 20.81 & 10.73 \\
Total & 34.47 & 2.17 & 50.31 & 4.70 & 25.13 & 10.12 & 16.11 & 4.96 \\
\hline
\end{tabular}

$* \mathrm{BSV}=$ Barren or sparsely vegetated.
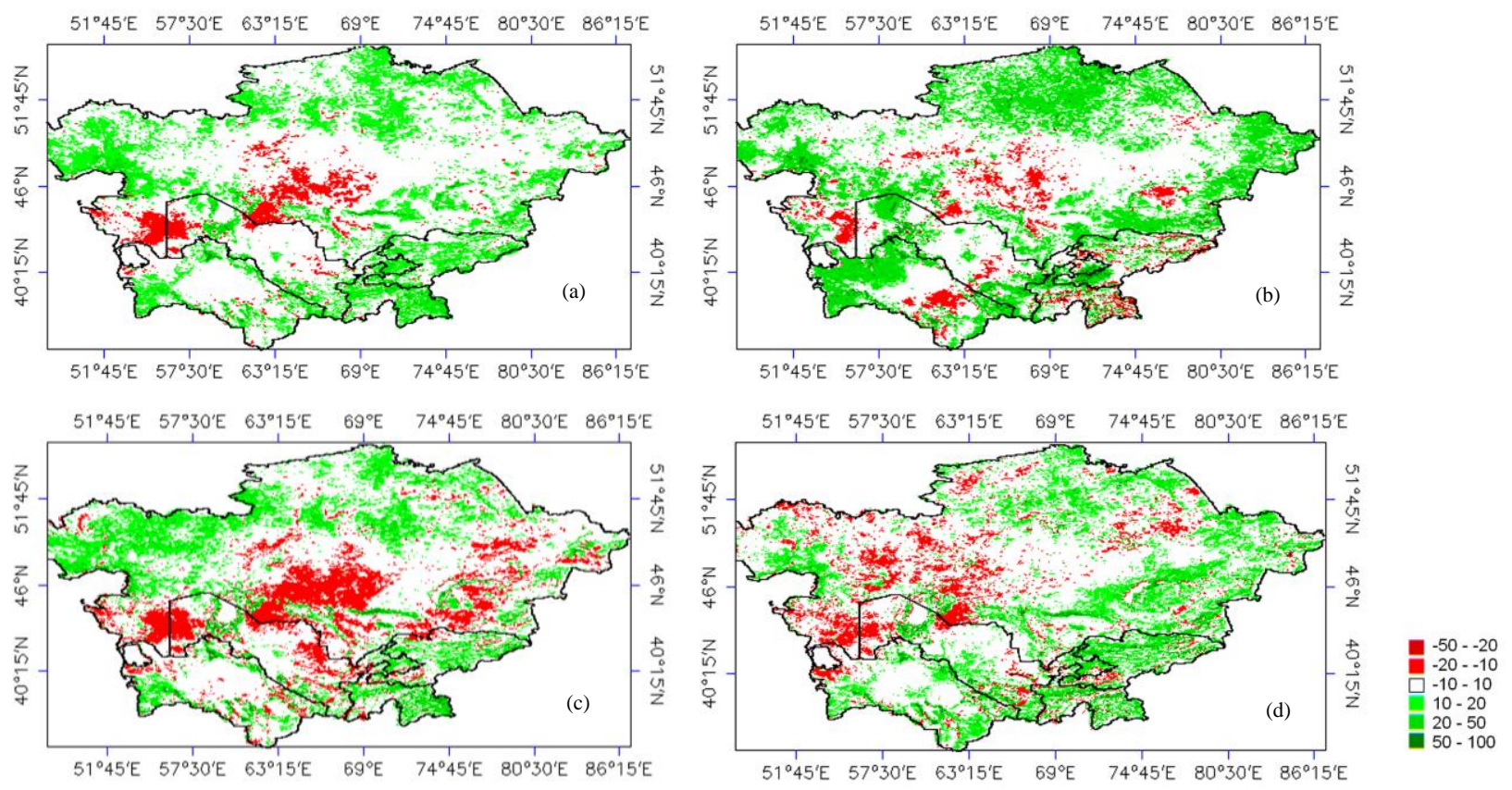

Figure 5. Spatial distribution of linear trends over 1982-2003 (in \% from the beginning of the period): (a) for growing season NDVI; (b) spring NDVI; (c) summer NDVI; (d) autumn NDVI. Coloured areas show statistically significant (p < 0.05 ) trends in NDVI. Grey areas indicate pixels with no significant trends in NDVI.

Li et al., 2002).

In order to find how much trends in spatially averaged NDVI can be explained by trends in precipitation we carried out correlation analysis between these variables. For all vegetated pixels with significant trends in NDVI, correlation between synchronous data of growing season NDVI and growing season precipitation was significant with $r=0.60$. For the individual land-cover categories, there was a strong statistical relationship between time-series of NDVI and precipitation (Table 6). Thus, the correlation coefficient was significant at 0.95 level and exhibited values $>0.50$ for cropland, irrigated cropland, cropland mosaic, savanna and BSV. Low values < 0.50 are observed in forested areas $(r=0.11)$ and in wetland $(r$
$=0.34)$. This result agree with the results obtained from other regions ( $\mathrm{Li}$ et al., 2002; Li et al., 2004; Wang et al., 2003), where NDVI in woody areas exhibit low sensitivity to interannual precipitation variability. An explanation may be that tree root system is capable to hold a great deal of moisture that can be released over time. This makes possible trees to grow without to be immediately affected by precipitation shortage in a dry year. Grass and shrub vegetations have much smaller root systems and can not hold moisture over a longer time. Greening patterns in wetland are only little controlled by precipitation on the locality, but more controlled by water charge in river system and overland run off.

We also analysed correlation between seasonal NDVI 
trends and trends in seasonal climate variables. Correlation analysis utilized the time-series of mean values of NDVI and precipitation amounts for spring (March to May), summer (June to August), and autumn (September to November). We found significant positive correlation coefficients for the timeseries of summer NDVI and summer precipitation (Table 6). Any combinations of data for other seasons did not exhibit any statistically significant relationships. Correlation coefficient between summer precipitation and summer NDVI values varied depending on land-cover type (Table 6). For cropland, cropland mosaic, shrubland and savanna, the correlation coefficients for summer season were higher than those calculated for the entire growing season.

\subsubsection{Relationship between Spatially Averaged NDVI Time- series and Temperature}

Temperature often serves as an indirect measure of available energy for plant growth. This energy is indispensable for plant growth. However, temperature also is a factor strongly limiting plant growth. Above a certain base temperature, a plant's rate of growth is found to be proportional to temperature until temperature reached an optimum value. If temperature overcomes this optimum value plants reduce the stomata or fully close them. Therefore, we have to expect positive correlations between temperature and NDVI in spring, early summer and autumn seasons but high summer, - when temperature climbs to its maximum values, - should be associated with negative correlations. We investigated and quantified temporal inter-relationships between vegetation dynamics and temperature on the inter-annual and inter-seasonal time-scales using corresponding time series of mean NDVI and mean temperature.

A strong significant relationship exists between timeseries of spring NDVI and spring temperature for all landcover classes and for all vegetated pixels (Table 6, last column). For the most land-cover types with exceptions of shrubland and BSV, the correlation coefficients exhibited values > 0.70. This result is in agreement with the results of other studies suggesting that productivity in northern high latitudes is increasing in response to increased temperatures especially during spring (Tucker et al., 2001; Xiao et al., 2004). The increase of spring temperature affects the spring NDVI values in two ways: first, through an earlier start of the growing season; and second, through a rapider climb of NDVI values during the spring months. For the most vegetation types with exception of shrubland and BSV, compared with temperature, precipitation plays a minor role as an explanatory factor for trends in NDVI over the study period. Shrubland and barren or sparsely vegetated areas (BSV) demonstrated higher dependence on rainfall than on temperature. It is clear that precipitation is the main climatic factor limiting vegetation development namely in these areas where evapotranspiration is more times higher than precipitation through the year. For the spatial average over all vegetated pixels, the weights of precipitation and temperature in explaining greenness patterns are in balance with correlation values of 0.75 and 0.76 , respectively.
Table 6. Correlation Coefficients between NDVI and Climatic Variables

\begin{tabular}{lllll}
\hline \multirow{2}{*}{ Land-cover } & \multicolumn{2}{c}{ Correlation } & \multicolumn{2}{c}{ Correlation } \\
& GDVI-precipitation & \multicolumn{2}{c}{ NDVI-temperature } \\
\cline { 2 - 5 } Cropland & 0.62 & 0.79 & 0.83 & -0.53 \\
Irr. Cropland & 0.54 & $*$ & 0.83 & $*$ \\
Cropland & 0.63 & 0.72 & 0.76 & -0.47 \\
Mos. & & & & \\
Grassland & 0.69 & 0.63 & 0.69 & -0.53 \\
Shrubland & 0.52 & 0.63 & 0.55 & -0.51 \\
Savanna & 0.56 & 0.76 & 0.82 & -0.43 \\
Wetland & 0.34 & 0.34 & 0.73 & $*$ \\
Forest & $*$ & 0.34 & 0.79 & $*$ \\
Tundra & 0.49 & 0.31 & 0.71 & $*$ \\
BSV & 0.57 & 0.34 & 0.39 & -0.55 \\
All pixels & 0.60 & 0.75 & 0.76 & $*$ \\
\hline
\end{tabular}

* means insignificant; the table only presents the combinations of the data which exhibit statistically significant relationship.

The analysis of the summer data revealed the presence of significant relationship in cropland, cropland mosaic, grassland, shrubland and savanna. The correlation coefficient showed negative values which were relatively low in comparison with the analysis of spring relations. In these cover types, temperature was assumed to be the factor influencing negatively the plant growth and its inter-annual dynamics. Any long-time increase of summer temperature reduces the photosynthetic activity of vegetation during the summer months. It is not surprisingly, that only land-cover types dominated by non-tree vegetation (grassland, shrubland) or by sparse tree vegetation (cropland mosaics, savanna) were proofed to be more or less affected by summer temperature. The adaptation of cultural crops, grasses and dwarf shrubs to the air moisture deficit caused by high temperatures is signifycantly worse than by tree plants. They start to reduce photosynthetic activity through closing stomata much earlier than trees. Therefore, forest did not exhibit any significant reaction to inter-annual variability of temperature in summer. So are wetland and tundra where moisture is available in sufficient amount throughout the growing season.

For autumn seasons and for the data averaged throughout the growing season we found no statistically significant relationship between temperature and the corresponding NDVI time-series.

\subsubsection{Spatial Patterns in Climate Effects on Trends in NDVI}

The results of the multiple correlation analysis revealed that most of the greening trends over Central Asia were driven by the climate change (Table 7). Over the entire region, about $75 \%$ of all pixels with statistically significant upward trend of the growing season NDVI exhibited strong correlation with the climate parameters. The percentage of explained trends was very high in cropland, irrigated cropland, cropland mosaic and savanna, with the value of $82.47,81.82,84.36$ and 
Table 7. The Total Number of Pixels with Significant upward/downward Trend and Number of Pixels Which Trends are Explained by Climate Change within each Land-Cover Type

\begin{tabular}{|c|c|c|c|c|c|c|}
\hline \multirow{3}{*}{ Land cover type } & \multicolumn{3}{|c|}{ Upward growing season trends } & \multicolumn{3}{|c|}{ Downward growing season trends } \\
\hline & \multirow{2}{*}{ Number of pixels } & \multicolumn{2}{|c|}{ Trends explained by climate } & \multirow{2}{*}{ Number of pixels } & \multicolumn{2}{|c|}{ Trends explained by climate } \\
\hline & & Pixels & $\%$ & & Pixels & $\%$ \\
\hline Cropland & 4718 & 3891 & 82.47 & 161 & 38 & 23.60 \\
\hline Irr. cropland & 2317 & 1896 & 81.82 & 70 & 16 & 22.85 \\
\hline Crop. Mos. & 7912 & 6675 & 84.36 & 284 & 59 & 20.77 \\
\hline Grassland & 5557 & 4035 & 72.61 & 381 & 192 & 50.39 \\
\hline Shrubland & 1907 & 1045 & 54.79 & 459 & 186 & 40.52 \\
\hline Savanna & 677 & 451 & 67.71 & 87 & 16 & 18.39 \\
\hline Wetland & 672 & 279 & 41.57 & 153 & 50 & 32.67 \\
\hline Forest & 1985 & 1190 & 59.90 & 150 & 59 & 39.33 \\
\hline Tundra & 74 & 30 & 40.54 & 5 & 2 & 40.00 \\
\hline BSV & 578 & 209 & 36.15 & 148 & 31 & 20.94 \\
\hline Total & 26387 & 19701 & 74.66 & 1898 & 647 & 34.08 \\
\hline
\end{tabular}

$72.61 \%$, respectively. These four land cover types have a decisive contribution to the total area of the explained trends. The lowest percentage of pixels with the climate-induced positive trends was observed in barren and sparsely vegetated areas, $36.15 \%$. Certainly, the weak influence of climate on the vegetation change in these areas is explained by a generally low correlation between the remotely sensed derived NDVI and climate parameters there. This problem has been good elucidated in recent studies (Wang et al., 2003; Li et al., 2002).

The results demonstrated a generally poor explanation of the downward NDVI by the climate factors. Only about $35 \%$ of all negative vegetation changes were coincided with significant coefficients of the multiple correlation (Table 7). The one third of these pixels were observed within grassland, and another one third in shrubland. This relatively low influence of climate on the negative trends allows us to assume a strong role of other factors driving the decrease of NDVI. One of the major from them should be a human activity. In spite of the strong reduce of the anthropogenic impact across the Central Asia, some local areas have experienced an increase of human impact during the study period. Such "hot spots" of the extensive human activity appeared particularly in the neighbouring environment of permanent settlements. After the collapse of the socialistic economic system the crop fields and pasture lands located a long way off from settlements have been abandoned as first, and the activity has been transferred to the lands located immediately near the settlements (Robinson et al., 2002). This tendency in the land use change caused an increase of human pressure on the environmental resources and started a degradation process at these places.

\section{Discussions}

In spite of the fact that the Central Asian Republics of the former Soviet Union occupy a great territory with an area of about 5.5 million $\mathrm{km}^{2}$ and represent a gigantic reservoir of organic carbon playing an important role in the global change, there is a lack of reports from this region in recent literature.
The entire contemporary knowledge about dynamics of climate and the vegetation change in the formerly Russian Central Asia has been based on the Russian-speaking publications from the Soviet era and a few modern reports by western scholars (DeBeurs and Henebry, 2004; Lubimtseva, 2005; Propastin and Kappas, 2008). However, the both scientific schools have been aware of the potential importance of this region in regards to the current climate change. The present study is one of the first works investigating the link between the inter-annual climate dynamics and vegetation change in Central Asia over the last two decades of the 20 century. The study used 22-years time series of the remotely sensing derived Normalized Difference Vegetation Index to discover regional and local responses of vegetation cover to global climate change and to reveal to what degree the local trends are caused by land use changes.

The results of our study revealed a general significant increase of vegetation activity across the most part of the Central Asia's territory. The results indicate an $11.35 \%$ increase in growing season NDVI in Central Asia between 1982 and 2003. The magnitude of the greening trend in the study region is consistent with similar trends reported for the northern high latitudes in Eurasia and North America by Tucker et al. (2001) and by Zhou et al. (2001) as well for China by Xiao and Moody (2004). However, the results demonstrated that the greening patterns are more widely extended as it has been reported from other regions. About $35 \%$ of all vegetated pixels exhibited positive trends in growing season NDVI. The percentage of area with increased NDVI varied substantively by land cover type, but was particularly high for cropland, irrigated cropland, cropland mosaics, and grassland. These four classes contributed about $75 \%$ to the total area undergoing greening. Shrubland and forest contributed an additional $18 \%$.

The significant trend in NDVI for all land cover types with exception of forest was strongly correlated with growing season and summer precipitation, while summer temperatures played a negative role and rather restrained photosynthetic activity in majority of the land cover types. Our results demon- 
strated a strong negative correlation between summer temperature and NDVI in cropland, cropland mosaics, grassland, shrubland, savanna and barren or sparsely vegetated areas. These results assume an increase of precipitation over broad areas of Central Asia, whereas the analysis of the correlation between NDVI and precipitation at per-pixel scale revealed clear spatial pattern in distribution across the region. About $20 \%$ of all pixels with significant growing season NDVI trend exhibited strong correlation with precipitation, the major part of these pixels was within cropland, cropland mosaics, and grassland in the northern part of the region. The explanation of the summer NDVI trends by summer precipitation was higher, about $65 \%$ of all pixels with significant upward trend correlated with summer rainfall. These results disagree with the conclusion by Xiao and Moody (2004) reported about very poorly explanation of the vegetation change by precipitation and a leading role of temperature in similar eco-climatic zones of China. We suggested that the dramatic drop of anthropogenic impact in Kazakhstan caused an enhancement of the vegetation response to climate, particularly to precipitation. In opposite to this, China's land use has been characterized by a significant increase of human impact during the same period. This caused a gradual decrease of the vegetation response to precipitation. The link between the sensitivity of the vegetation cover to rainfall and the degree of human influence has been thoroughly discussed by Veron et al. (2006), whereas Evans and Geerken (2004) used this link for a degradation assessment in Jordanian drylands.

All vegetation types demonstrated a strong upward trend in spring NDVI between 1982 and 2003. The significant upward trend in spring NDVI occurred in $50 \%$ of the total vegetated area but the percentage varied by land-cover type. We found positive relationship between spring temperature and spring NDVI in each land cover type. Speaking about spatial patterns of this relationship, for $66 \%$ of the entire area with the upward spring trend, this positive trend was strongly correlated with spring temperature. The results from spring suggest that there is an overall enhancement of NDVI in the early growing season, and that much of that enhancement can be explained by spring temperatures. This is consistent with the results reported from the high latitudes in Eurasia and North America by (Tucker et al., 2001; Zhou et al., 2001) and from China by (Xiao and Moody, 2004). Nonetheless, for Central Asia the spatial extension of the area undergoing the greening trend of spring NDVI was significantly greater than in China during the similar period, $50 \%$ against $25 \%$ of the total vegetated area, respectively. Cropland, irrigated cropland, cropland mosaics, grassland and shrubland contributed about $80 \%$ to the total area undergoing greening.

The negative trends of NDVI were observed in all analysed seasons and within each land cover type, but they occurrence was relatively rarely. Thus, among all trends in growing season NDVI only $2.17 \%$ were negative. Summer season was characterized by the most often occurrence of the downward trend of NDVI with the overall percentage of $10.12 \%$. Concerning the growing season trend, cropland mosaics, grassland, shrubland, and barren/sparsely vegetated areas contributed about $70 \%$ of the total area undergoing a decrease of the vegetation cover over the study period. The results of this study demonstrated a generally strong control of greening trends by temperature and precipitation. The complex of climatic factors combined in a multiple regression model explained more than $75 \%$ of all upward trends in growing season NDVI across the region. Especially high percentages of pixels with greening trends explained by the multiple climate effect were observed in cropland, irrigated cropland, cropland mosaics and grassland. Xiao and Moody (2004) considered the improvement of crop management practice to be the main factor enhancing the productivity of vegetation in China's cropland. Therefore, they found rather a weak explanation of the greening trends in the cropland by precipitation and temperature. In contradiction to this report from China, the results of our study suggested the climate change to be the prevalent driving force for the greening trend in the agriculturally used land cover types. The process of the massive abandonment of crop fields and pastures throughout the region caused an enormous reduce of anthropogenic influence and, as a consequence, a significant regeneration of the vegetation cover in broad areas of the region. The response of vegetation to climate, particularly to precipitation, should be increasing during the period of this land use change. This fact is reflected in the high percentage of the upward NDVI trends explained by the combine climate effect.

In opposite to the greening trends, the explanation of the downward trends was rather poorly. Only about $34 \%$ of all negative NDVI trends could be considered to be driven by the climate change. We suggested that the majority of the decreasing NDVI trends were the result of human activity. As it was being discussed above, human impact generally reduces the response of vegetation to climate, and, on the contrary, a diminishing human influence enhances this response. Taking into account this fact, it is not surprisingly, that we had the poor explanation of downward trends by climate. The majority of these trends should be attributed to the change of land use practice enforcing an abandonment of agricultural-used lands located far away from the permanent settlements and a concentration of the human activity to the lands located near the settlements.

However, we have to declare that any interpretation of the human impact degree in vegetation changes is rather based on speculations. Thus, trends in NDVI that resulted from the changes in land cover and land use cannot be fully separated from trends due to climatic factors. Another source for uncertainty in the end results and their interpretation is the duration of the study period (1982 to 2003). The 22-year period is a short record for studies on vegetation trends and climate change. Thus, precipitation in drylands is known to have a very high inter-annual variability. Years with extremely high precipitation amount may be characterized by extremely high vegetation production and introduce bias to statistical assessment of the trends. Nevertheless, in spite of all shortcoming of the study, the study results improve the understanding of the nature and mechanisms of the ecosystem dynamics in the inner Eurasia and provide the basis for predicting changes in 
productivity that accompany change in climate and human activity.

\section{Consclusions}

This study has demonstrated that the potential in using NDVI for monitoring the long-time vegetation change and its climatic correlates in the former Soviet Republics of Central Asia. The NDVI data derived from the Advanced High Resolution Radiometer (AVHRR) were successfully combined with gridded datasets of precipitation and temperature to model the effect of climate change and to detect areas of high response to climatic conditions during the period of 1982 to 2003. The broad-scale increases in photosynthetic activity across the region is consistent with recent environmental change and can be ascribed to two main causes: first, the contemporary climate change (primarily global warming and redistribution of precipitation over the territory); and second, a drastic change of human activity caused by the transition from socialistic to liberal economic system.

We found an overall $11.35 \%$ increase in growing season NDVI. The increases in spring and summer NDVI over the same time period were 13.58 and $9.23 \%$, respectively. Thirtyfive percent of entire vegetated area of Central Asia exhibited upward trends in growing season NDVI. Trends in spring NDVI occurred in 50\% of all vegetated pixels and was considered to be the major contributor to the growing season trend. Summer NDVI increased in $25 \%$ of all vegetated pixels. Cropland, cropland mosaic, grassland and shrubland taking the most area of the study region accounted for the majority of these increases. The results suggest a strong climate impact on seasonal and growing season trends in vegetation activity. There were notable areas of the increases in the growing season NDVI (75\% of all pixels with a significant upward trend) that exhibited a strong correlation with the complex of climatic parameters. Downward trends occurred in $2.17 \%$ of the total area and were suggested to have primarily anthropogenic origin. Only $35 \%$ of all pixels with downward trend revealed a significant correlation with the combination of climatic factors. Thus, the observed trends in NDVI result from the combined effects of climate and land use change in the study region. The interaction between climate and human impact can vary significantly among vegetation types but its joint effect on vegetation cover is the main explanatory factor for changes in vegetation activity. The findings of this study have contributed to a better understanding of the inter-annual and interseasonal relations between NOAA AVHRR/NDVI and ecoclimatic variables in a dry inner region of Eurasia.

Acknowledgments. This study was carried out as a part of a large international project "Dry land management and rural development in Central Kazakhstan" with a financial support of the Academy of Science of Kazakhstan.

\section{References}

Anyamba, A. and Tucker, C.J. (2005). Analysis of Sahelian vegeta- tion dynamics using NOAA-AVHRR NDVI data from 1981-2003, J. Arid Environ., 63(3), 596-614, doi:10.1016/j.jaridenv.2005.03.0 07.

Anyamba, A., Tucker, C.J. and Eastman, J.R. (2001). NDVI anomaly patterns over Africa during the $1997 / 98$ ENSO warm event, Int. J. Remote Sens., 22(10), 1847-1859, doi:10.1080/014311600100291 56.

Chen, Z.M., Babiker, I.S., Chen, Z.X., Komaki, K., Mohamed, M.A.A. and Kato, K. (2004). Estimation of interannual variation in productivity of global vegetation using NDVI data, Int. J. Remote Sens., 25(16), 3139-3159, doi:10.1080/0143116032000160435.

DeBeurs, K.M. and Henebry, G.M. (2004). Land surface phenology, climatic variation, and institutional change: analysing agricultural land cover change in Kazakhstan, Remote Sens. Environ., 89(4), 497-509, doi:10.1016/j.rse.2003.11.006.

Evans, J. and Geerken, R. (2005). Discrimination Between Climate and Humane-Induced Dryland Degradation, J. Arid Environ., 57, 535-554, doi:10.1016/S0140-1963(03)00121-6.

Foody, G.M. (2003). Geographical weighting as a further refinement to regression modelling: an example focused on the NDVI-rainfall relationship, Remote Sens. Environ., 88, 283-293, doi:10.1016/j.rs e.2003.08.004.

Friedl, M.A., McIver, D.K., Hodges, J.C., Zhang, X.Y., Muchoney, D., Strahler, A.H., Woodcock, C.E., Gopal, S., Schneider, A., Cooper, A., Baccini, A., Gao, F. and Schaaf, C. (2002). Global land cover mapping from MODIS: algorithms and early results, Remote Sens. Environ., 83, 287-302, doi:10.1016/S0034-4257(02) 00078-0.

Gutman, G., Csiszar, I. and Romanov, P. (2000). Using NOAA/ AVHRR products to monitor El Nino impacts: focus on Indonesia in 1997-98, Bull. Am. Meteorol. Soc., 81, 1188-1205, doi:10.1175/ 1520-0477(2000)081<1189:UNPTME>2.3.CO;2.

Herrman, S.M. and Huttchinson, C.F. (2005). The changing content of the desertification debate, J. Arid Environ., 63(3), 538-555, doi: 10.1016/j.jaridenv.2005.03.003.

Holben, B.N. (1986). Characteristics of maximum-value composite images from temporal AVHRR data, Int. J. Remote Sens., 7(11), 1417-1434, doi:10.1080/01431168608948945.

IPCC, 2001. Third assessment report of the Intergovernmental Panel on Climate Change, Cambrige, Cambrige University Press.

Justice, C.O., Townshend, J.R.G., Holben, B.N. and Tucker, C.J. (1985). Analysis of the phenology of global vegetation using meteorological satellite data, Int. J. Remote Sens., 6(8), 1271-1318, doi:10.1080/01431168508948281.

Kawabata, A., Ichi, K. and Yamaguchi, Y. (2001). Global Monitoring of Inter-annual Changes in Vegetation Activities Using NDVI and its Relationship to Temperature and Precipitation, Int. J. Remote Sens., 22(7), 1377-1382, doi:10.1080/01431160119381.

Kogan, F.N. (1997). Global drought watch from space, B. Am. Meteorol. Soc., 78, 621-636, doi:10.1175/1520-0477(1997)078<06 21:GDWFS>2.0.CO;2.

Li, B., Tao, S. and Dawson, R.W. (2002). Relation between AVHRR NDVI and ecoclimatic parameters in China, Int. J. Remote Sens., 23(5), 989-999, doi:10.1080/014311602753474192.

Li, J., Lewis, J., Rowland, J., Tappan, G. and Tieszen, L. (2004). Evaluation of land performance in Senegal using multi-temporal NDVI and rainfall series, J. Arid Environ., 59(3), 463-480, doi:10. 1016/j.jaridenv.2004.03.019.

Lioubimtseva, E., Cole, R., Adams, J.M. and Kapustin, G. (2005). Impacts of climate and land-cover changes in arid lands of Central Asia, J. Arid Environ., 62, 285-308, doi:10.1016/j.jaridenv.2004.11. 005.

Los, S.O. (1993). Calibration Adjustment of the NOAA AVHRR Normalized Difference Vegetational Index Without Resource to Component Channel 1 and 2 Data, Int. J. Remote Sens., 14(10), 
1907-1917, doi:10.1080/01431169308954011.

Mainguet, M. (1999). Aridity: drought and human development, Berlin, Springer-Verlag.

McCloy, K.R., Los, S., Lucht, W. and Hojsgaard, S. (2005). A comparative analysis of three long-term datasets derived from AVHRR satellite data, EARSeL eProceedings, 4, 52-70.

Myneni, R.B., Keeling, C.D., Tucker, C.J., Asrar, G. and Nemani, R.R. (1997). Increased plant growth in the northern high latitudes from 1981 to 1991, Nature, 386, 698-702, doi:10.1038/386698a0.

Myneni, R.B., Tucker, C.J., Asrar, G. and Keeling, C.D. (1998). Inter-annual variations in satellite-sensed vegetation index data from 1981 to 1991, J. Geophys. Res., 103, 6145-6160.

New, M., Hulme, M. and Jones, P.D. (2000). Global monthly climatology for the twentieth century, Data set, Available online. http://ww w.daac.ornl.gov.

Nicholson, S.E. and Farrar, T.J. (1994). The influence of soil type on the relationships between NDVI, rainfall and soil moisture in Semiarid Botswana. I. NDVI response to rainfall, Remote Sens. Environ., 50, 107-120.

Petrov, M.P. (1976). Deserts of the World, Wiley, Chichester, pp. 447.

Pinzon, J.E., Brown, M.E. and Tucker, C.J. (2004). Global Inventory Modeling and Mapping Studies (GIMMS) AVHRR 8-km Normalized Difference Vegetation Index (NDVI) dataset. Product Guide. http://glcf.umiacs.umd.edu/data/gimms/.

Potter, C.S. and Broocks, V. (1998). Global analysis of empirical relations between annual climate and seasonality of NDVI, Int. J. Remote Sens., 19, 2921-2948, doi:10.1080/014311698214352.

Propastin, P. and Kappas, M. (2008). Reducing uncertainty in modelling the NDVI-precipitation relationship: a comparative study using global and local regression techniques, GISci. Remote Sens., 45 (1), 1-21. doi:10.2747/1548-1603.45.1.47.

Richard, Y. and Poccard, I. (1998). A statistical study of NDVI sensitivity to seasonal and inter-annual rainfall variations in southern Africa, Int. J. Remote Sens., 19(15), 2907-2920, doi:10.1080/0143 11698214343.

Robinson, S., Milner-Gulland, E.L. and Alimaev, I. (2002). Rangeland degradation in Kazakhstan during the Soviet-era: re-examining the evidence, J. Arid Environ., 53(3), 419-439, doi:10.1006/ja re.2002.1047.

Tateishi, R. and Ebata, M. (2004). Analisis of phonological change patterns using 1982-2000 Advanced Very High Resolution Radiometer (AVHRR) data, Int. J. Remote Sens., 25, 2287-2300, doi:10. 1080/01431160310001618455.

Tucker, C.J. and Nicholson, S.E. (1999). Variations in the size of the Sahara Desert from 1980-1997, Ambio, 28, 587-591.

Tucker, C.J. and Sellers, P.J. (1986). Satellite remote sensing of primary vegetation, Int. J. Remote Sens., 7(11), 1395-1416, doi:10.10 80/01431168608948944.

Tucker, C.J., Slayback, D.A., Pinzon, J.E., Los, S.O., Muneni, R.B. and Taylor, M.G. (2001). Higher northern latitude Normalized Difference Vegettion Index and growing season trends from 1982 to 1999, Int. J. Biometeorol., 45, 184-190.

Tucker, C.J., Pinzon, J.E., Brown, M.E., Slayback, D., Pak, E.W., Mahoney, R., Vermote, E. and El Saleous, N. (2005), An Extended AVHRR 8-km NDVI Data Set Compatible with MODIS and SPOT Vegetation NDVI Data, Int. J. Remote Sens., 26(20), 44855598, doi:10.1080/01431160500168686.

Veron, S.R., Paruelo, J.M. and Osterheldt, M. (2006). Assessing desertification, J. Arid Environ., 66, 751-763, doi:10.1016/j.jaridenv. 2006.01.021.

Wang, J., Rich, P.M. and Price, K.P. (2003). Temporal responses of NDVI to precipitation and temperature in the central Great Plains, USA, Int. J. Remote Sens., 24(11), 2345-2364, doi:10.1080/01431 160210154812.

Xiao, J. and Moody, A. (2004). Trends in vegetation activity and their climatic correlates: chin 1982 to 1998, Int. J. Remote Sens., 25(24), 5669-5689, doi:10.1080/01431160410001735094.

Yang, L., Wylie, B., Tieszen, L.L. and Reed, B.C., (1998). An analysis of relationships among climate forcing and time-integrated NDVI of grasslands over the U.S. Northern and Central Great Plains, Remote Sens. Environ., 65, 25-37, doi:10.1016/S0034-425 7(98)00012-1.

Young, S.S. and Harris, R. (2005). Changing patterns of global-scale vegetation photosynthesis, 1982-1999, Int. J. Remote Sens., 26: 4537-4563, doi:10.1080/01431160500239198.

Zhou, L., Tucker, C.J., Kaufmann, R., Slayback, D., Shabanov, N. and Myneni, R.B. (2001). Variations in northern vegetation activity inferred from satellite data of vegetation index during 1981 to 1999, J. Geophys. Res., 106, 20069-20083, doi:10.1029/2002JD00 3046. 